\title{
Parameters Affecting the Mechanical Refining Process of Plant Raw Materials Using a Jet-impingement Method
}

Larisa V. Yurtayeva,* Yuri D. Alashkevich, Roman A. Marchenko, Darya Yu. Vasilieva, and Eugene V. Kaplyov

Different types of rotor-stator and jet-impingement refining equipment are used depending on the methods of production of fibre semi-finished products and on the initial state of raw materials. This article examines various refining modes for jet-impingement devices and their influence on the physical and mechanical properties of the processed material. Main design parameters that affect the refining process in this type of plant were determined. It was shown that the time required to refine a fibre mass using this plant depends on the jet flow rate (from the nozzle to the barrier), i.e. as the jet flow rate increases, the time required to refine the fibre mass decreases. A dimensionless machine parameter was obtained that characterises the effectiveness of the refining process and the design of jet-impingement refining plants. Using the dimensional method, a functional dependence was observed of breaking length, bursting strength, folding strength, and tearing strength on the machine complex parameter. The numerical value of the machine complex parameter was determined, depending on refining duration.

Keywords: Cellulose; Refining; Knifeless refiner; Disc mill; Pulp; Physical and mechanical characteristics; Refining degree

Contact information: M. F. Reshetnev Siberian State University of Science and Technologies, 31 Prospect imeni gazety "Krasnoyarsky rabochiy", 660037, Krasnoyarsk, Russia;

* Corresponding author: 2052727@mail.ru

\section{INTRODUCTION}

The mechanical strength of paper is a function of the properties of a fibre suspension. An initial fibre suspension that changes its properties during the refining process can be characterised by the following indicators: average fibre length, water retention capacity, and interfibre bonding forces; these variables have the most significant effect on the strength of paper (Korda et al. 1967; Ivanov 2006; Gu et al. 2018). The properties of the paper to be produced depend both on the type of initial fibres and on how they are processed at all stages of paper production, as well as on the refining process (Hon 1996; Heinze et al. 2006; Kamitakahara et al. 2008).

Refining equipment is designed to divide various semi-finished products into fibres, to mill fibres, and give them certain properties (Pettersen 1984; Krässig 1993; Qu et al. 2011). Different types of rotor-stator and jet-impingement refining equipment are used depending on the methods of production of fibre semi-finished products and on the initial state of raw materials (Shurkina et al. 2019; Vasilyeva et al. 2019).

Refining is one of the most important operations in paper production. Many properties of paper depend largely on this process. Unrefined fibres form a loose and lowstrength sheet that is not acceptable in structure and appearance (Alashkevich 1980). This is due to the fact that relatively rigid and long fibres go through a flotation process and are deposited on the mesh, forming a bulky sheet; the outer surface and flexibility of the fibres 
are poorly developed, and as a result the strength of the sheet is low. Unrefined fibres are poorly hydrated; therefore, such fibres do not bond well with each other in paper sheets. Fibre shortening is not the primary purpose of the refining process. In most cases, splitting fibres longitudinally into extremely thin fibrils is more important (Käyhkö et al. 2020). It has been established that the basic refining action in rotor-stator refining devices takes place in the gap clearance between movable rotor bars and fixed stator bars (Sharpe 1991).

As for jet-impingement refining devices (Shemyakin 1973; Veretnov 1973; Goncharov et al. 1979; Konturri 2005; Erofeyeva et al. 2010), a fibre suspension is developed as a result of three main actions:

- Tangential shear stresses as the suspension flows through the extension and bit

- A suspension jet hitting against the barrier upon leaving the bit

- A cavitation effect as a liquid flows along the barrier

Cavitation involves the generation of breaks in the continuity of the fluid phase in the flow of a liquid or suspension. These breaks occur at those points in the flow where a significant local pressure drop takes place as a result of pressure redistribution caused by the liquid motion (Kanavellis 1968).

A considerable amount of research related to such processes as fibre material refining and refining machine design improvement has been conducted both in the Russian Federation and abroad (Vasyutin 1987; Kovalyov et al. 2009; Flyate 2012; Kaplyov et al. 2019; Kaplyov et al. 2020). However, most of these works are fragmented and concentrate on solving specific problems. For this reason, in the authors' view, studies on the effectiveness of refining equipment operation are relevant and can be conducted based on the knowledge of hydrodynamic processes taking place upon interaction of working elements of a refining device with a specified fibre suspension.

The goal is to find an analytical dependence between the main properties of paper obtained when refining in a jet-impingement refining device and its design parameters.

\section{EXPERIMENTAL}

\section{Cellulose}

Bleached and unbleached sulphate softwood cellulose (BSSC) (a semi-finished product from Ilim Group, OJSC, Bratsk) with a concentration of $2 \%$ and water release level of 16 degrees Schopper-Riegler ( $\left.{ }^{\circ} \mathrm{SR}\right)$ was used as the study subject.

\section{Measurements}

The following laboratory methods were used to control the refining process:

- $\quad{ }^{\circ}$ SR measurements were carried out in accordance with ISO 5267-1 (1999);

- laboratory sheets were made in accordance with ISO 5269-1 (2005);

- tensile, burst, and tear strength were measured in accordance with ISO 5270 (2012), ISO1974 (2012), and ISO 1924-2 (2008).

Technical characteristics of experimental jet-impingement refining plants are shown in Table 1. 
Table 1. Technical Specifications of a "Jet-impingement" Type of Refining Test Device

\begin{tabular}{|l|l|}
\hline Plant dimensions (length $\times$ width $\times$ height) & $4.3 \times 1.6 \times 2.0 \mathrm{~m}$ \\
\hline Actuating hydraulic cylinder, piston type: & $0.1 \mathrm{~m}$ \\
\hline Internal diameter & $1.2 \mathrm{~m}$ \\
\hline Rod stroke & $0.091 \mathrm{~m}$ \\
\hline Operating hydraulic cylinder, piston type: & $1.2 \mathrm{~m}$ \\
\hline Internal diameter & 2 \\
\hline Rod stroke & $0.77 \times 10^{-3} \mathrm{~m}^{3} / \mathrm{sec}$ \\
\hline Pump station gear-type hydraulic pump NSh-2: & $0-13 \mathrm{MPa}$ \\
\hline Capacity & Diesel oil DP-11 \\
\hline Operating pressure & $\mathrm{AO}-51-4-02,2 \mathrm{pcs}$ \\
\hline Working medium & $24.3 \mathrm{~s}^{-1}$ \\
\hline Electric motor & $0.45 \times 0.65 \mathrm{~m}$ \\
\hline Rotor RPM & \\
\hline $\begin{array}{l}\text { Combined refining node (diameter } \\
\text { height) }\end{array}$ & $0.35 \mathrm{~m}$ \\
\hline Pelton turbine: & $24 \mathrm{pcs}$ \\
\hline Diameter & \\
\hline Number of vanes & \\
\hline
\end{tabular}

\section{Refining Tests}

The Industrial Technology and Machine Engineering Department of M. F. Reshetnev Siberian State University of Science and Technologies (Krasnoyarsk, Russia) holds a research group dedicated to studying pulp materials refining using both rotor-stator and jet-impingement refining methods. The process of cellulose refining with the use of refining machines is understood to depend not only on design and process parameters, but also on morphological properties of fibers (Sedov 1981; Sharpe 1991; Bridgman 2001).

A $2 \%$ fibre mass was stirred using a hydrobeater for $20 \mathrm{~min}$. A centrifugal pump was used to convey it from the circulation tank 1 through the conical nozzle 4 to the barrier 5 (Fig. 1). The plant consists of a mechanism that creates operating parameters of the jet 2 , 3 , and the movable barrier 5 .

In case of multiple passes, fibre masses are milled to the required degree of refining, as characterized by the Schopper-Riegler $\left({ }^{\circ} \mathrm{SR}\right)$ value.

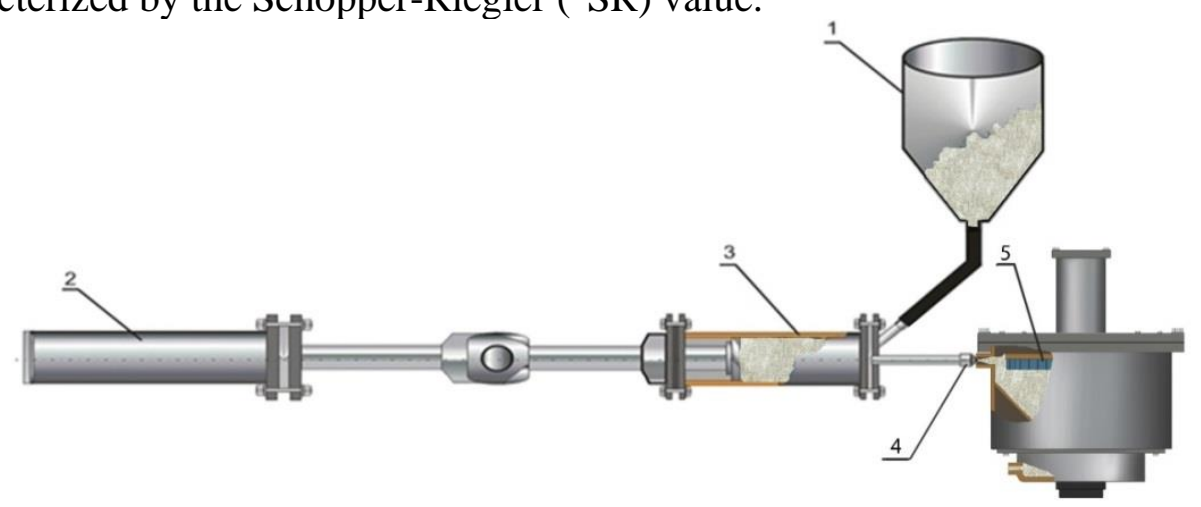

Fig. 1. "Jet-impingement" type refining plant. 1 - Vessel; 2 - actuating cylinder; 3 - operating cylinder; 4 - bit; and 5 - movable barrier 


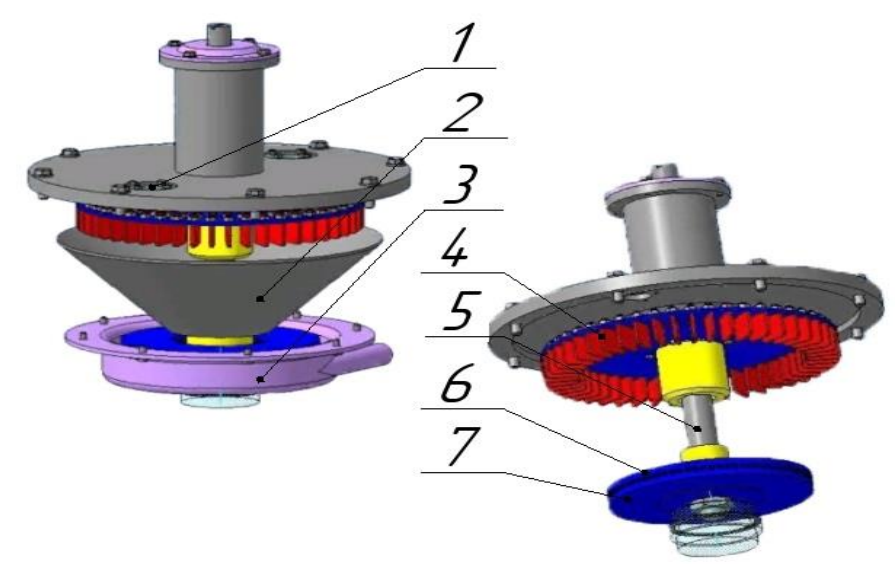

Fig. 2. Combined rotor-stator refining node: 1 - Combined refining node body; 2 - Cone; 3 rotor-stator type refining chamber; 4 - Turbine; 5 - Shaft; 6 - Tackle stationary disc; and 7 tackle movable disc

\section{RESULTS AND DISCUSSION}

\section{Theoretical Proof of the Complex Parameter of the Effectiveness of the Refining Process Using a Jet-impingement Refining Device}

The process of fibrous pulp refining using a "jet-impingement" type refining machines is defined by a system of parameters $\delta^{\prime}, \rho, t, E, d, \alpha, C$, and ${ }^{\circ} \mathrm{SR}$, and it can be described through a functional dependence by Eq. 1 ,

$$
f=\left(\delta^{\prime}, \rho, t, E, d, \alpha, C,{ }^{\circ} S R\right)=0
$$

where $f$ denotes function; $\delta$ ' is the distance (m) from bit to barrier; $\rho$ represents motion pulse $(\mathrm{kg} \cdot \mathrm{m} / \mathrm{sec}) ; t$ is refining time (s); $E$ denotes specific energy consumption $(\mathrm{J} / \mathrm{kg}) ; d$ is bit diameter (m); $\alpha$ is bit taper angle $\left({ }^{\circ}\right) ; C$ denotes processed pulp concentration $\left(\mathrm{kg} / \mathrm{m}^{3}\right)$; and ${ }^{O} R$ is freeness as per Schopper-Riegler $\left({ }^{\circ}\right)$.

Taking into account the system of units where main units are length, mass, and time $(L, M, T)$, dimensionless combinations were composed, as per $\pi$ - of theorem (Sedov 1981; Bridgman 2001).

The Pi-theorem makes it possible to establish the general structure of the dependence. The basis of the dimension analysis is the position that all mathematical equalities expressing the relationship between physical quantities (parameters of the fluid flow) must be dimensionally homogeneous or homogeneous in dimensions.

$$
\varphi\left(\frac{\delta^{\prime}}{d} ; \frac{\rho \cdot t}{C \cdot \delta^{\prime 4}} ; \frac{d}{\delta^{\prime}} ; \alpha ;{ }^{\circ} \mathrm{SR}\right)=0
$$

In Eq. 2, $\varphi$ is a function; $\frac{\delta^{\prime}}{d}$ is the first dimensionless parameter, $\frac{\rho \cdot t}{C \cdot \delta^{\prime 4}}$ is the second dimensionless parameter; and $\frac{d}{\delta^{\prime}}$ is the third dimensionless parameter.

By expressing one of the dimensionless parameters via the other ones, the required values were found. Thus, upon solving Eq. 2 against a dimensionless parameter, 


$$
\frac{\rho \cdot t}{C \cdot \delta^{\prime 4}}
$$

the following Eq. 3 is obtained:

$$
\begin{aligned}
& \frac{\rho \cdot t}{C \cdot \delta^{\prime^{4}}}=\varphi\left(\frac{\delta^{\prime}}{d} ; \frac{d}{\delta^{\prime}} ; \alpha ;{ }^{\circ} \mathrm{SR}\right) \\
& \text { or } \quad C \cdot \delta^{\prime 4} \varphi\left(\frac{\delta^{\prime}}{d} ; \frac{d}{\delta^{\prime}} ; \alpha,{ }^{0} \mathrm{SR}\right) \\
& \rho=\frac{\rho}{\rho}
\end{aligned}
$$

As demonstrated by Eqs. 3 and 4 using the dimensional method, the time required to refine fibrous pulp of the specified quality at this plant depends on jet flow rate; i.e., with the increase of rate the time required to process the pulp is decreasing.

The impact of other parameters was determined by experimental study, since obtaining a theoretical definition of function $\varphi(2)$ by solving the differential equation of motion of ground fibrous pulp entails significant mathematical complications. As a result, a dimensionless parameter was obtained, characterizing the design of the "jet-barrier" type refining device (parameter of the effectiveness of the refining process using a jetimpingement refiner):

$$
K_{\mathrm{m}}=\frac{\rho \cdot t}{C \cdot \delta^{\prime 3} \cdot d}
$$

Dependence between refining degree as per Schopper-Riegler and the value of machine complex parameter $K_{\mathrm{m}}$ (Fig. 3) was determined.

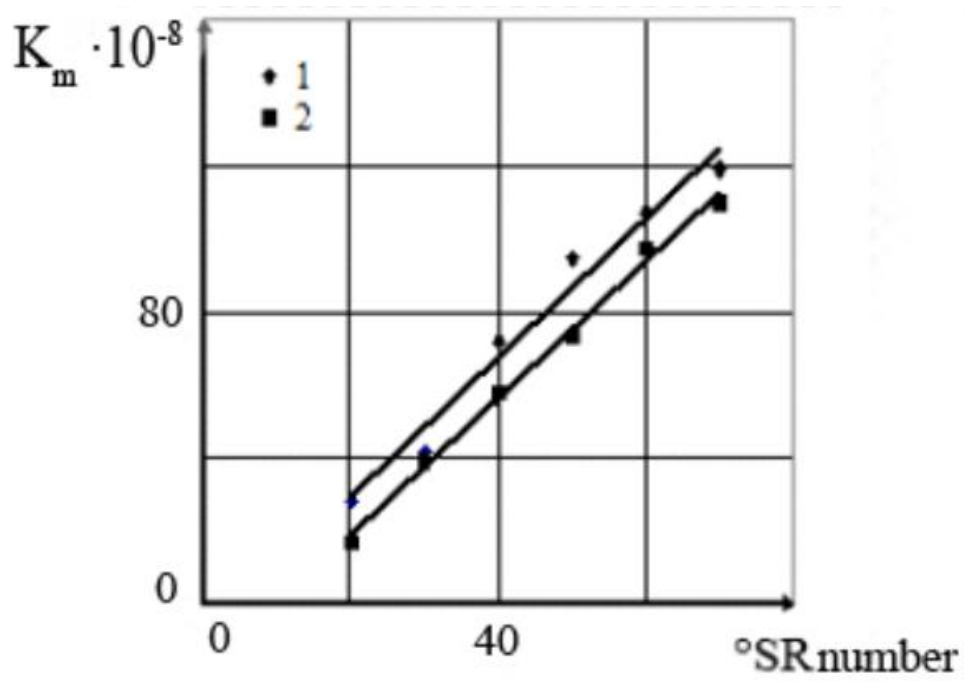

Fig. 3. Dependence of machine complex parameter on refining degree as per Schopper-Riegler: 1 - for bleached cellulose; and 2 - for unbleached cellulose 
For straight lines (Fig. 3), the values of slope ratio $K$ and free term $B$ were calculated using the least squares method, as demonstrated below.

For bleached cellulose, with $K=21.5 \cdot 10^{7}$ and $B=-1500 \cdot 10^{6}$, then

$$
K_{\mathrm{m}}=21.5 \cdot 10^{7}\left({ }^{\circ} \mathrm{SR}-6.9\right)
$$

For unbleached cellulose, with $K=19.6 \cdot 10^{7}$ and $B=-2220 \cdot 10^{6}$ :

$$
K_{\mathrm{m}}=19.6 \cdot 10^{7}\left({ }^{\circ} \mathrm{SR}-11.3\right)
$$

That is, as the degree of pulp milling continues to grow, the quantitative value of the $K_{\mathrm{m}}$ parameter increases and, therefore, so does the effectiveness of the refining process using a jet-impingement refining plant.

\section{Influence of the Complex Parameter of the Effectiveness of the Refining Process Using a Jet-impingement Refining Plant on the Strength Properties of Finished Castings}

Upon regression analysis, equations were obtained showing correlation between strength characteristics of finished sheets and machine complex parameters (Figs. 4 and 5).

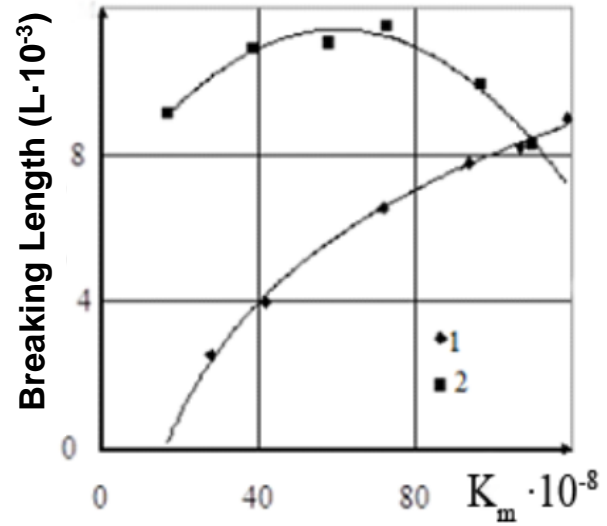

a)

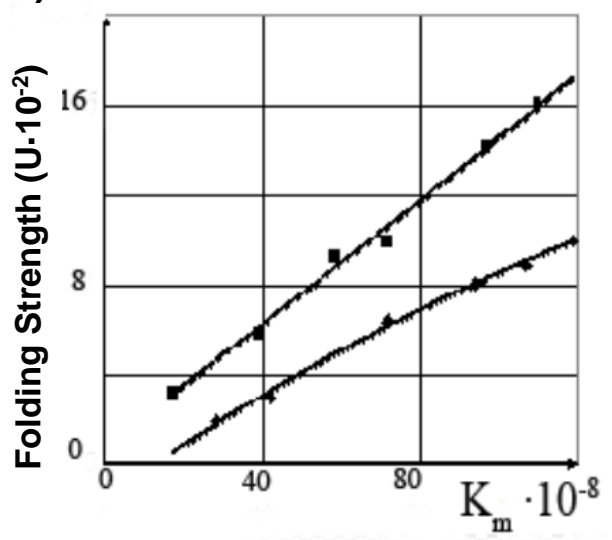

c)

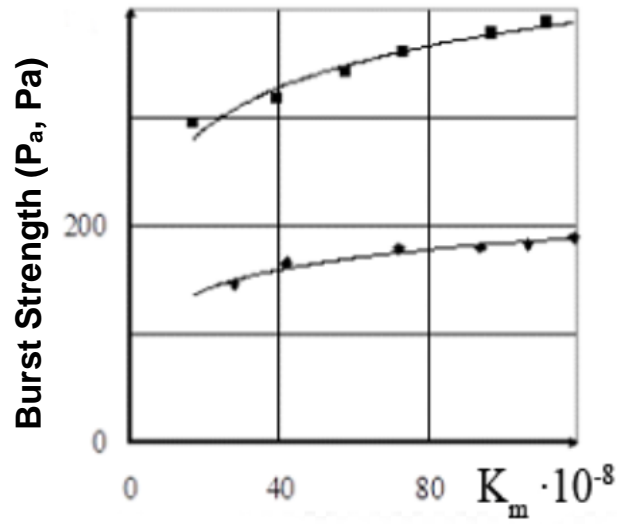

b)

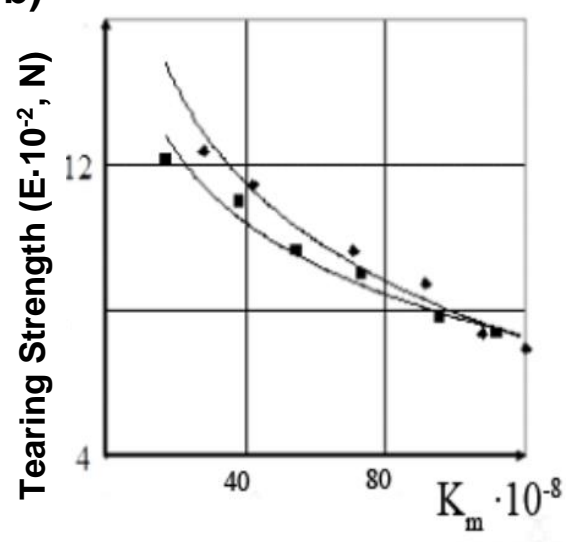

d)

Fig. 4. Dependency of machine complex parameters on physical and mechanical properties of finished sheets: 1 - Bleached cellulose; 2 - unbleached cellulose; $a$ - breaking length; $b$ - burst strength; $\mathrm{c}-$ folding strength; and $\mathrm{d}-$ tearing strength. 
Functional dependencies are represented by Eqs. 8 through 15 and Fig. 4. For the breaking length of bleached cellulose:

$$
L=4414.2 \cdot \ln K_{\mathrm{m}}-93624,
$$

For unbleached cellulose:

$$
L=-10^{-16} \cdot K_{\mathrm{m}}^{2}+10^{-16} \cdot K_{\mathrm{m}}+6913.8 .
$$

For burst strength of bleached cellulose:

$$
P_{\mathrm{a}}=26.71 \cdot \ln K_{\mathrm{m}}-431.73,
$$

For burst strength of unbleached cellulose:

$$
P_{\mathrm{a}}=55.09 \cdot \ln K_{\mathrm{m}}-891.23 \text {. }
$$

For folding strength of bleached cellulose:

$$
U=3 \cdot 10^{-9} \cdot K_{\mathrm{m}}^{1,15},
$$

For folding strength of unbleached cellulose:

$$
U=3 \cdot 10^{-6} \cdot K_{\mathrm{m}}{ }^{0,86} \text {. }
$$

For tearing strength of bleached cellulose:

$$
E=9659.7-385.01 \cdot \ln K_{\mathrm{m}},
$$

For tearing strength of unbleached cellulose:

$$
E=7247.8-280.83 \cdot \ln K_{\mathrm{m}} .
$$

Analytical dependence (Eqs. 8 to 15 ) between the basic properties of paper obtained in the refining process and the structural and technological parameters of a jet-impingement refining plant allow us to:

- Broaden the understanding of how the structural and mechanical properties of paper are formed in the process of its production;

- Select design and technological parameters of equipment and initial raw materials in order to control the quality of fibre material products to obtain the required quality of paper.

\section{CONCLUSIONS}

1. Fibre suspensions are processed in jet-impingement refining devices as a result of tangential shear stresses as a suspension flows in an extensional mode during its collision with a hard surface.

2. A complex parameter was developed to characterize the effectiveness of the refining process using a jet-impingement refining device, which depends on the flow rate of a fibre suspension from a nozzle, the concentration of the processed mass, and the design aspects (distance from the nozzle to the barrier and the nozzle diameter). The developed complex parameter of the effectiveness of the refining process has made it possible to come closer to solving the issue regarding the mechanism of the refining process for fibre semi-finished products using a jet-impingement refining device. 
3. The dependence of an increase in the degree of refining of fibre semi-products was determined experimentally relative to the concentration and the type of fibre semiproducts, taking into account the complex parameter of the refining process effectiveness. As shown by the experimental results, the indices of an increase in the degree of refining and the influence of fibre suspension concentrations were consistent with the theoretical analysis of the refining process mechanism.

4. Functional dependencies between basic physical and mechanical properties of the finished product and the machine complex parameter were obtained for the purpose of practical use of the complex parameter related to fiber suspension treatment process using the jet-impingement method.

\section{ACKNOWLEDGMENTS}

The study was carried out under the Government Order issued by the Ministry of Education and Science of Russia for "Deep Conversion of Plant Material" by the Research Laboratory team under the project "Technology and Equipment for Plant Biomass Chemical Processing" (subject number: FEFE-2020-0016).

\section{REFERENCES CITED}

Alashkevich, Y. D. (1980). Foundations of the Theory of Hydrodynamical Processing of Fibrous Materials Using Grinding Machines, Ph.D. Dissertation, Saint Petersburg, $334 \mathrm{pp}$.

Bridgman, P. (2001). Dimensional Analysis, Izhevsk, 148 pp., p. 45.

Erofeyeva, A. A., Alashkevich, Yu. D., and Baranovsky, V. P. (2010). "Analysis of distribution of suspension jet rate during its flow through "jet-barrier" type grinding plant working bodies," Lesnoy Vestnik No.4, pp. 157-160.

Flyate, D. M. (2012). in: Paper Properties, D. M. Flyate (ed.), Saint Petersburg, Lan'.

Goncharov, V. N., Gauze, A. A., and Alikin, V. P. (1979). Machines for Defibration and Knifeless Grinding of Paper Pulp, Leningrad, LTA, 106 p.

$\mathrm{Gu}, \mathrm{F}$., Wang, W., and Cai, Z. (2018). "Water retention value for characterizing fibrillation degree of cellulosic fibers at micro and nanometer scales," Cellulose 25(5), 2861-2871. DOI: 10.1007/s10570-018-1765-8

Heinze, T., Liebert, T., and Koschella, A. (2006). Esterification of Polysaccharides, Structure of Polysaccharides, Springer, Berlin

Hon, D. N.-S. (1996). Chemical Modification of Lignocellulosic Materials, Marcel

Dekker Inc., New York. DOI: 10.1201/9781315139142

Ivanov, S. N. (2006). Paper Technology, Moscow, Shkola bumagi, 696 pp.

Kamitakahara, H., Koschella, A., Mikawa, Y., Nakatsubo, F., Heinze, T., and Klemm, D., (2008). "Synthesis and characterization of 2,6-di-O-methyl cellulose both from natural and synthetic cellulose," Macromolecular Bioscience 8(7), 690-700.

DOI:10.1002/mabi.200700291

Kanavellis, R. (1968). "Jet blow and cavitation fracture," in: Theoretical Fundamentals of Engineering Calculations, Moscow, No. 3 (V. 90), pp. 39-48.

Kaplyov, E. V., Yurtayeva, L. V., and Alashkevich, Y. D. (2019). "Impact of grinding 
mode on physical and mechanical properties of bleached sulphate cellulose," in: Problems of Pulp-and-paper Material Mechanics, Arkhangelsk, pp. 87-93.

Kaplyov, E. V., Yurtayeva, L. V., and Frolov, A. S. (2020). "Parameters of fiber suspension jet turbulence," in: New Advances in the Plant Material Chemistry and Chemical Technology, Barnaul, Gorno-Altaisk State University Press, pp. 223-226.

Käyhkö, J., Hiltunen, E., Hiltunen, Y., Nikolskaya, E., Kulmala, L, and Maloney, T. C. (2020). "Effect of compression refining on fiber properties," BioResources 15(4), 8696-8707.

Konturri, E. J. (2005). Surface Chemistry of Cellulose: From Natural Fibres to Model Surfaces, Ph.D. Dissertation. Technische Universiteit Eindhoven, Niedereland, 145 pp.

Korda, I., Libnar, Z., and Prokop, I. (1967). Grinding of Paper Stock, The Forest Industry, Moscow, $420 \mathrm{pp}$.

Korda, Zh., Libnar, Z., and Prokop, Yu. (1967). Grinding of Paper Stock (translation from Czech), Moscow, The Forest Industry.

Kovalyov, V. I., Yerofeeva, A. A., and Alashkevich, Yu. D. (2009). "Dependence of basic physical parameters on temperature in knifeless grinding plant upon jet contact with barrier," in: New Advances in the Plant Material Chemistry and Chemical Technology, Barnaul, Gorno-Altaisk State University Press, pp. 219-221.

Krässig, H. A. (1993). Cellulose: Structure, Accessibility and Reactivity, Gordon and Breach, Pennsylvania

Pettersen, R. C. (1984). "The chemical composition of wood," Advances in Chemistry 207, 57-126. DOI: 10.1021/ba-1984-0207.ch002

Qu, T., Guo, W., Shen, L., Xiao, J., and Zhao, K. (2011). "Experimental study of biomass pyrolysis based on three major components: hemicellulose, cellulose, and lignin," Industrial and Engineering Chemistry Research 50(18), 10424-10433.

DOI: 10.1021/ie1025453

Sedov, L. I. (1981). Similarity and Dimensional Methods in Mechanics, Moscow, Nauka. Sharpe, P. E. (1991), Pulp \& Paper DIV, TAPPI, Quebec, Canada

Shemyakin, E. V. (1973). Study of Mechanisms of Cellulose Fibers Grinding Using Knifeless Machines, PhD Dissertation, Saint Petersburg, 156 pp.

Shurkina, V. I., Marchenko, R. A., and Alashkevich, Yu. D. (2019). "Research of the paper-forming properties of a fibrous material with the use of a tacking with curvilinear knives," IOP Conference Series: Materials Science and Engineering 467. DOI: 10.1088/1757-899X/467/1/012002

Vasilyeva, D. Yu., and Yurtayeva, L. V. (2019). "Vliyaniye sposoba razmola na fibrillyatsiyu voloknistoi massy (Impact of grinding method upon fibrous mass fibrillation)," in: Molodiye Ucheniye v Reshenii Aktualnikh Zadach [Young Scientists Addressing Current Scientific Challenges], Krasnoyarsk, M. F. (ed.), Reshetnev SibSU, pp. 137-140.

Vasyutin, V. G. (1987). Intensification of the Process of Combined Grinding of Cellulose Suspensions, PhD Dissertation, Krasnoyarsk, 166 pp.

Veretnov, A. K. (1973). Study of Impact of Force Interactions on the Process of Cellulose Grinding in Knife-based Machines and Development of Tackle Design for its Hydro-dynamic Processing, Ph.D. Dissertation, Krasnoyarsk, 159 pp.

Article submitted: Dec. 2, 2020; Peer review completed: March 6, 2021; Revised version received and accepted: April 28, 2020; Published: April 30, 2021.

DOI: $10.15376 /$ biores.16.2.4212-4220 